\title{
Erratum to: Landiolol: A Review of its use in Intraoperative and Postoperative Tachyarrhythmias
}

\author{
Greg L. Plosker
}

Published online: 2 July 2013

(C) Springer International Publishing Switzerland 2013

Erratum to: Drugs (2013) 73:959-977

DOI 10.1007/s40265-013-0077-4

A Published-Ahead-of-Print version of this article was made available online on 13 June 2013. An error has subsequently been identified in that version of the article, and the following correction should be noted:

Reviewer affiliations: Z. Wajima's affiliation details were incorrect and should appear as Department of Anesthesiology, Shioya Hospital, International University of Health and Welfare, Tochigi, Japan.

The online version of the original article can be found under doi:10.1007/s40265-013-0077-4.

G. L. Plosker $(\bowtie)$

Adis, 41 Centorian Drive, Private Bag 65901, Mairangi Bay,

North Shore 0754, Auckland, New Zealand

e-mail: demail@springer.com 